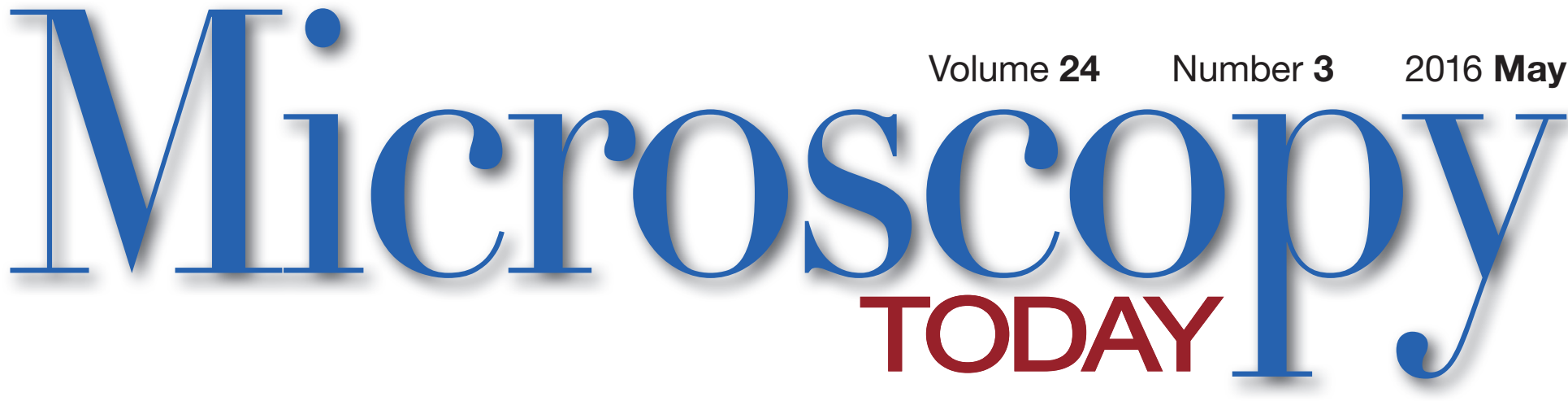

Volume $24 \quad$ Number 32016 May
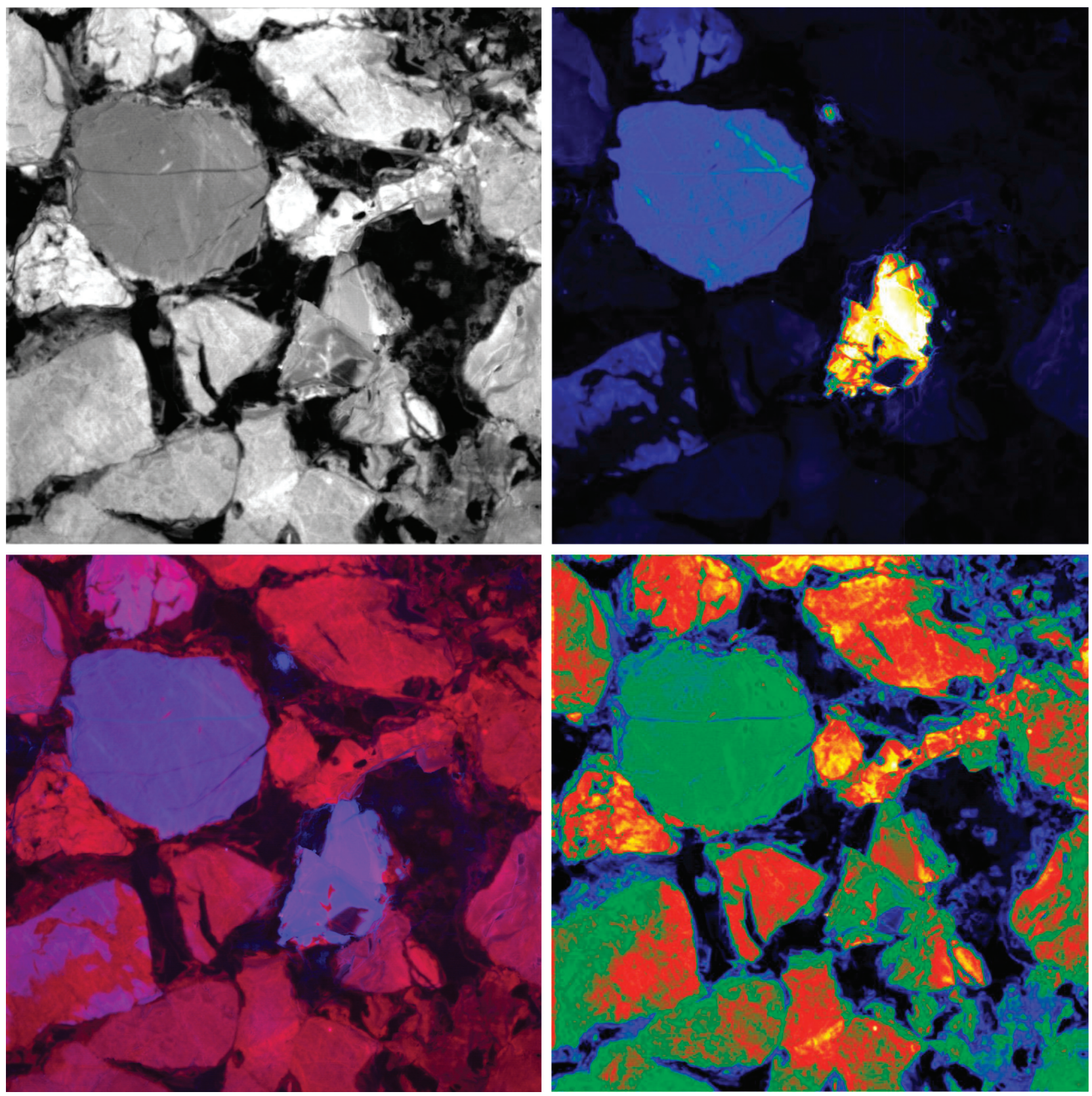


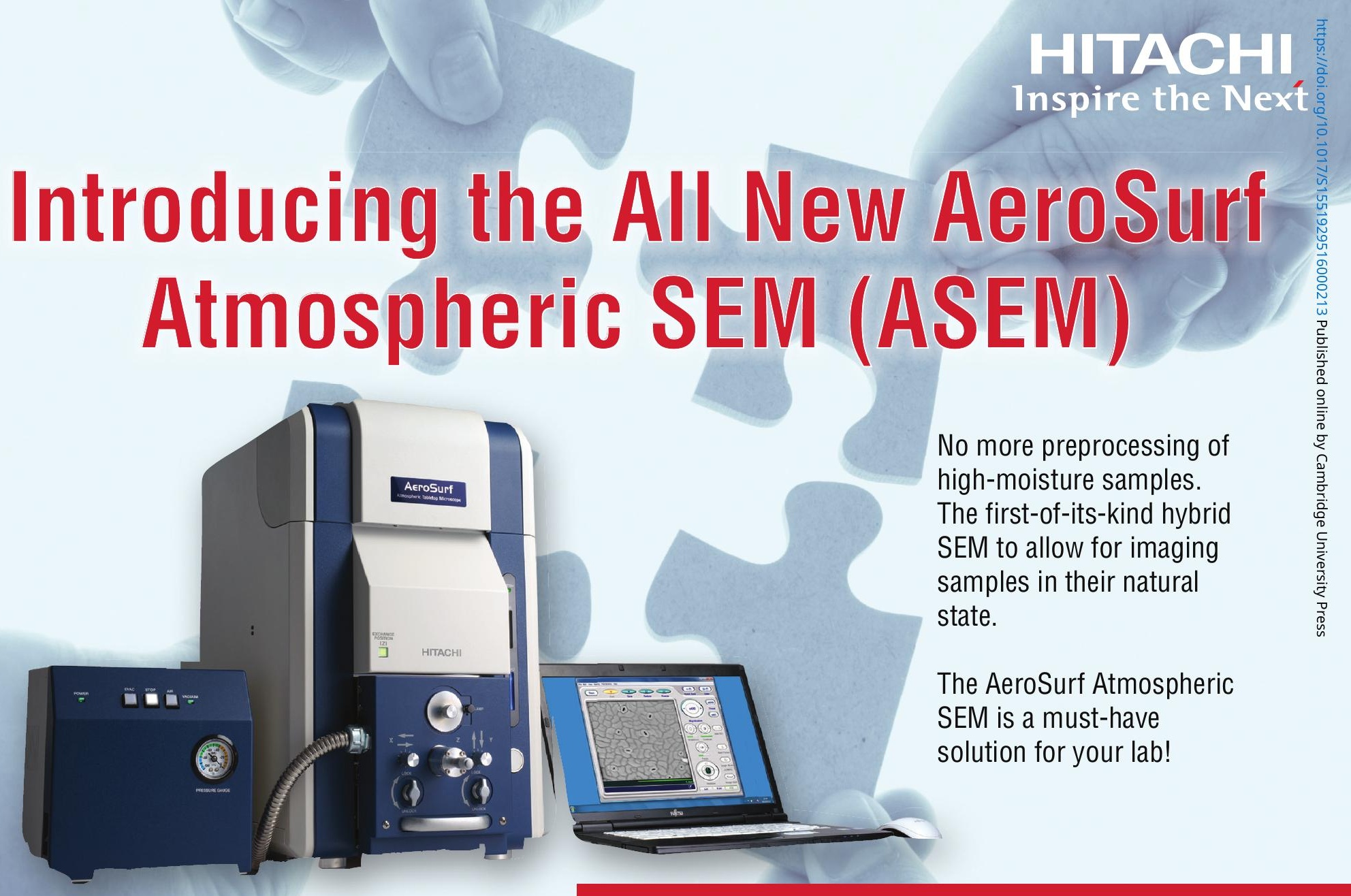

Request a demo or product info: microscopy@hitachi-hta.com

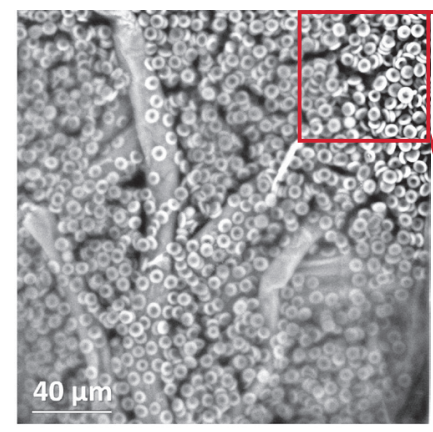

Magnification: 500x

Sample: Blood cells

Acceleration voltage: $15 \mathrm{kV}$

Pressure: Atmospheric $(101 \mathrm{kPa})$

Temperature: Room temperature

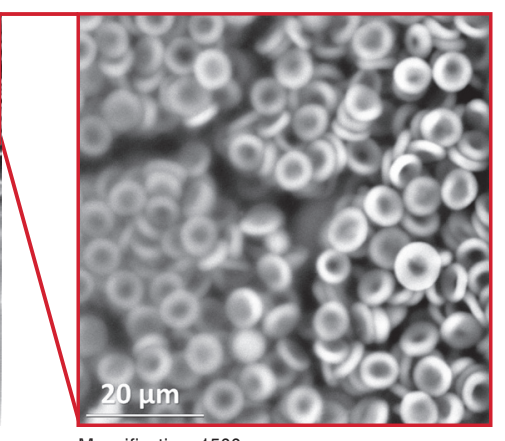

Magnification: $1500 x$
The AeroSurf-a hybrid tabletop atmospheric scanning electron microscope (ASEM)-has an extremely thin membrane which separates the evacuated column and the atmospheric-pressure chamber, enabling the observation of typically difficult specimens, such as bulk or wet samples, in their natural state, without the need for often damaging and time-consuming preprocessing.

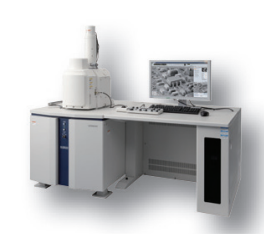

VP-SEM, FE-SEM \& FIB

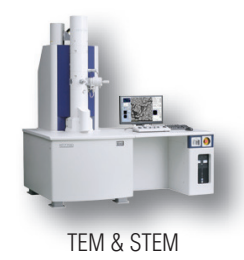

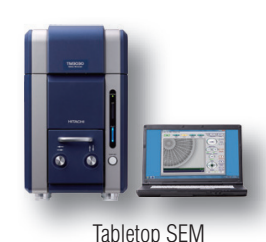

Tabletop SEM
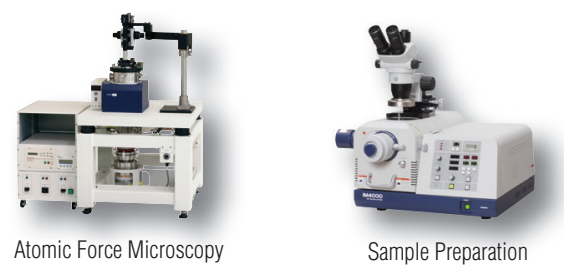

\section{Inspire Innovation through Collaboration}

Hitachi High Technologies America, Inc.

www.hitachi-hightech.com/us

800-253-3053 
Visit the meeting website often for details on

Symposia, Exhibits, Biological and Physical Sciences Tutorials,

$$
\text { In-Week Intensive Workshops, Posters, }
$$

Sunday Short Courses and Pre-Meeting Congresses
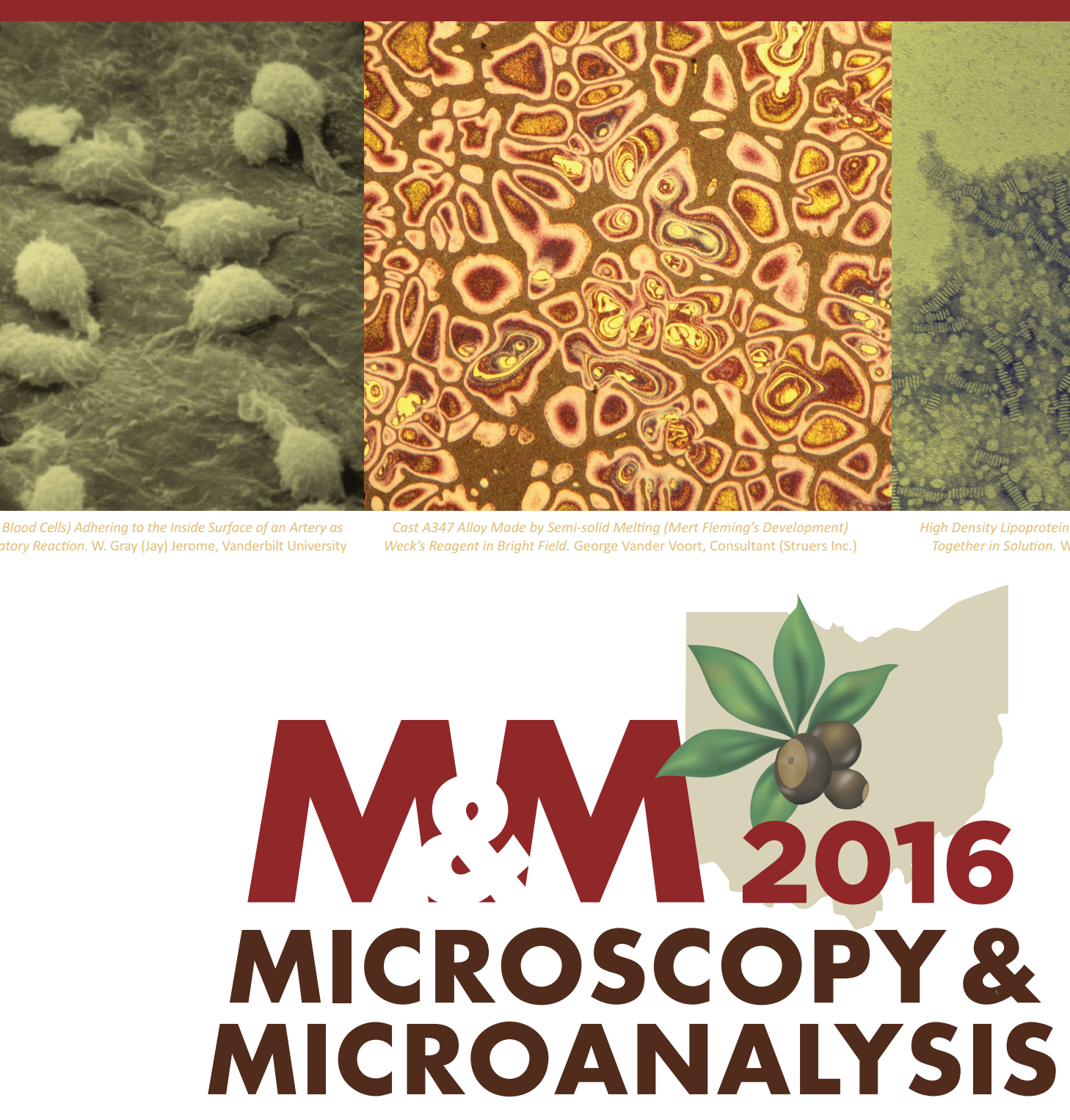

July 24-28, 2016 - Columbus, Ohio

\section{http://microscopy.org/MandM/2016}

Program Information | Information for Students | Meeting Awards | Exhibitor List \& Floor Plan Registration (opens February 2016) | Columbus Hotel Information (reservations available February 2016) 


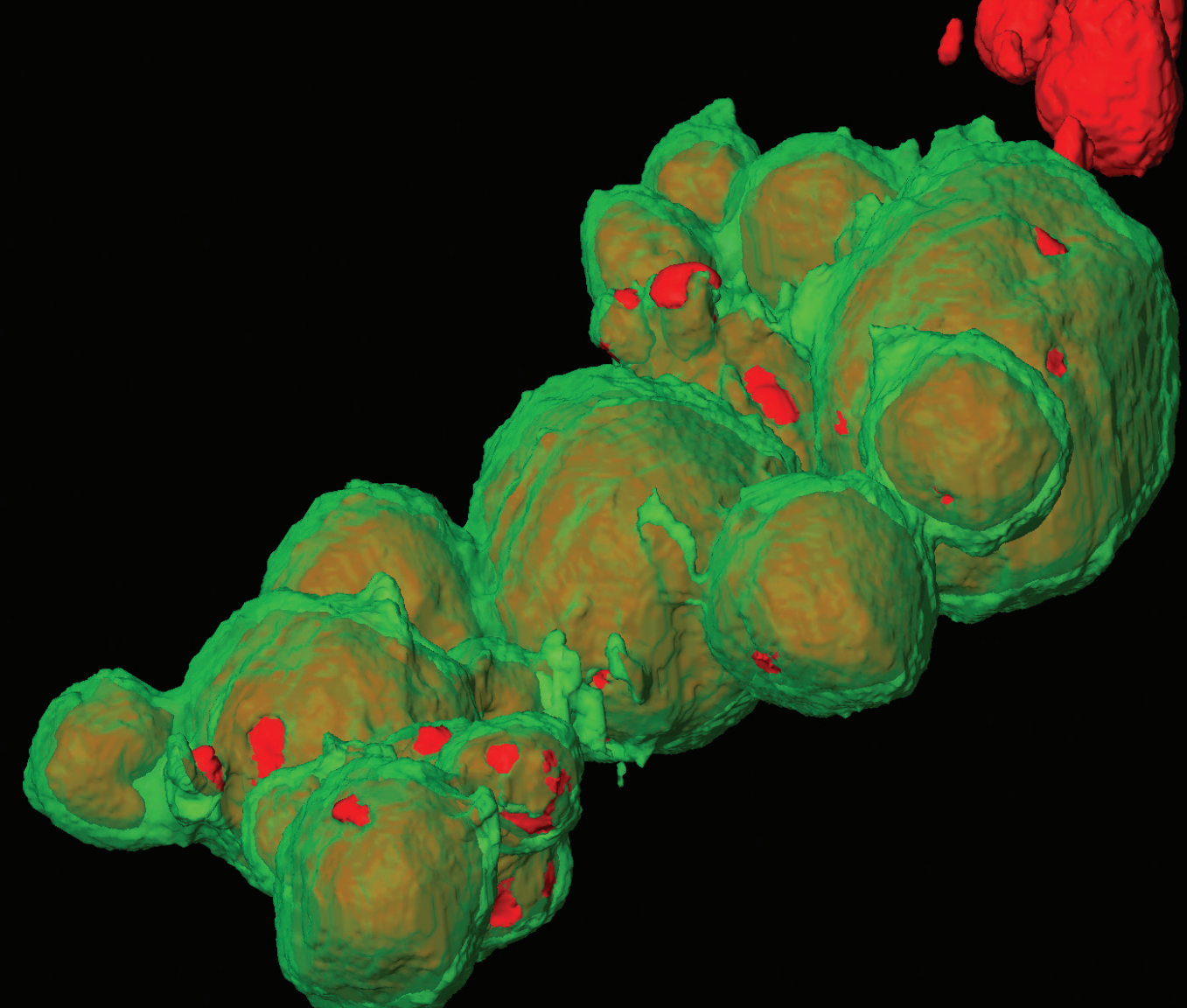

B

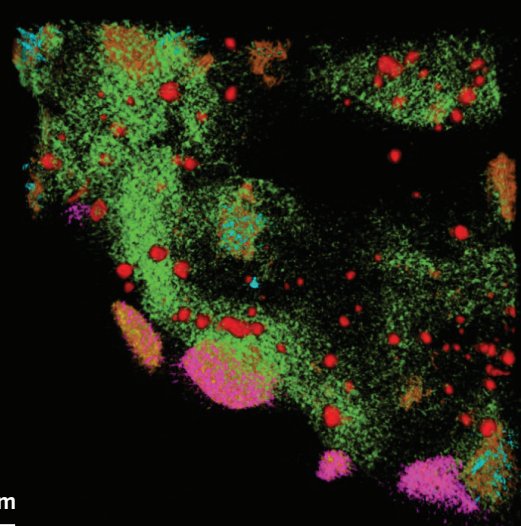

c

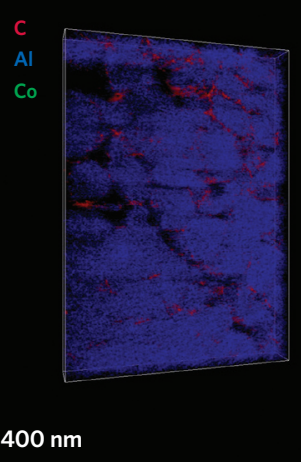

(D)

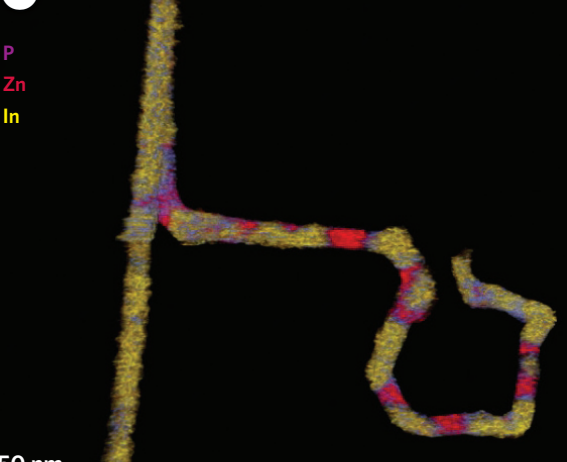

$50 \mathrm{~nm}$

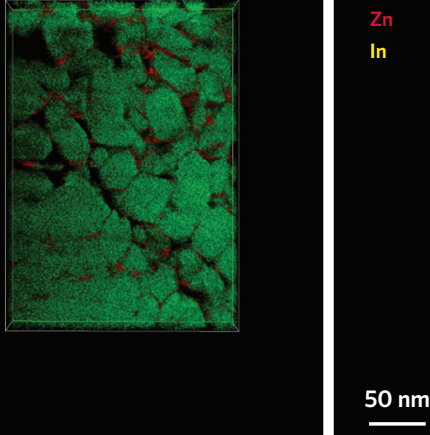

A: EDS tomogram of Ag-Pt core-shell nanoparticles. Ag cores are shown in the false color of red, covered by green-colored Pt shells, only a few nanometers in thickness. Sample courtesy Prof. Yi Ding and

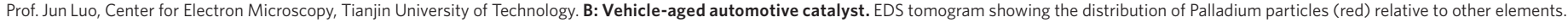
C: Battery anode material. EDS tomograms of Carbon-Cobalt and Carbon-Aluminum. D: EDS tomogram of P-Zn-In nanotubes. Sample Courtesy of Dr. Reza Shahbazian Yassar, Michigan Tech University.

\section{Automated 3D EDS with Talos}

The ability to perform compositional analysis and visualize the resulting chemical maps in 3D is essential to characterize the true elemental distribution and structure of modern nanomaterials-delivering new insights into structure-function relationships.

Contact your FEl representative today to see how advanced materials characterization methods such as quantitative energy dispersive X-ray (EDS) analysis can bring new heights of discovery to your research.

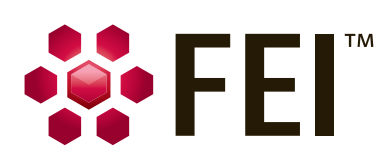

Discover more at FEl.com/Talos 


\section{Contents}

About the Cover

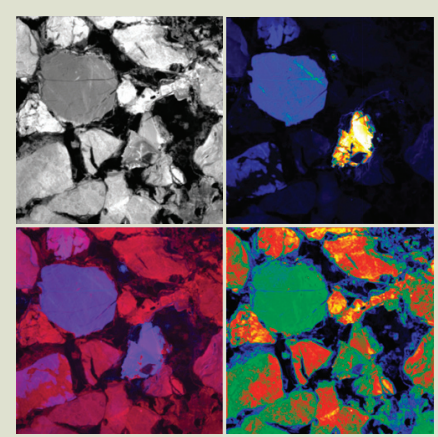

Cathodoluminescence imaging of quartz. Clockwise from upper left: CL grayscale image, CL image at $450 \mathrm{~nm}, C L$ image at $600 \mathrm{~nm}$, and blue-on-red composite image. Image width $=350 \mu \mathrm{m}$.

See article by Coenen et al.

\section{Microscopy}

\section{Feature Article}

12 A New Cathodoluminescence System for Nanoscale Optics, Materials Science, and Geology

T. Coenen, S. V. den Hoedt, and A. Polman

\section{Electron Microscopy}

20 Image Contrast in Energy-Filtered BSE Images at Ultra-Low Accelerating Voltages

Yoichiro Hashimoto, Atsushi Muto, Eric Woods, Todd Walters, and David C. Joy

26 Combined Tilt- and Focal-Series Tomography for HAADF-STEM Tim Dahmen, Holger Kohr, Andrew R. Lupini, Jean-Pierre Baudoin, Christian Kübel, Patrick Trampert, Philipp Slusallek, and Niels de Jonge

\section{Focused Ion Beam Technology}

$32 \mathrm{Xe}^{+}$Plasma FIB: 3D Microstructures from Nanometers to Hundreds of Micrometers

T. L. Burnett, B. Winiarski, R. Kelley, X. L. Zhong, I. N. Boona, D. W. McComb, K. Mani, M. G. Burke, and P. J. Withers

\section{Light Microscopy}

40 Exploring the Depths: Matching Light Microscopy Techniques to Applications

Samuel Bonfig and Alec De Grand

\section{Scanning Probe Microscopy}

44 High-Resolution Nanochemical Mapping of Soft Materials Martin Wagner and Thomas Mueller

52 Preparation of Stainless Steel Surfaces for Scanning Probe Microscopy

Alexander D. Warren, Ana I. Martinez-Ubeda, Oliver D. Payton, Loren Picco, and Tom B. Scott

\section{Pioneers}

56 Pioneers in Optics: Tycho Brahe Eric Clark

\section{Departments}

7 Editorial

8 Carmichael's Concise Review

58 Industry News

60 Product News
62 NetNotes

66 Calendar of Meetings

73 Dear Abbe

74 Index of Advertisers 


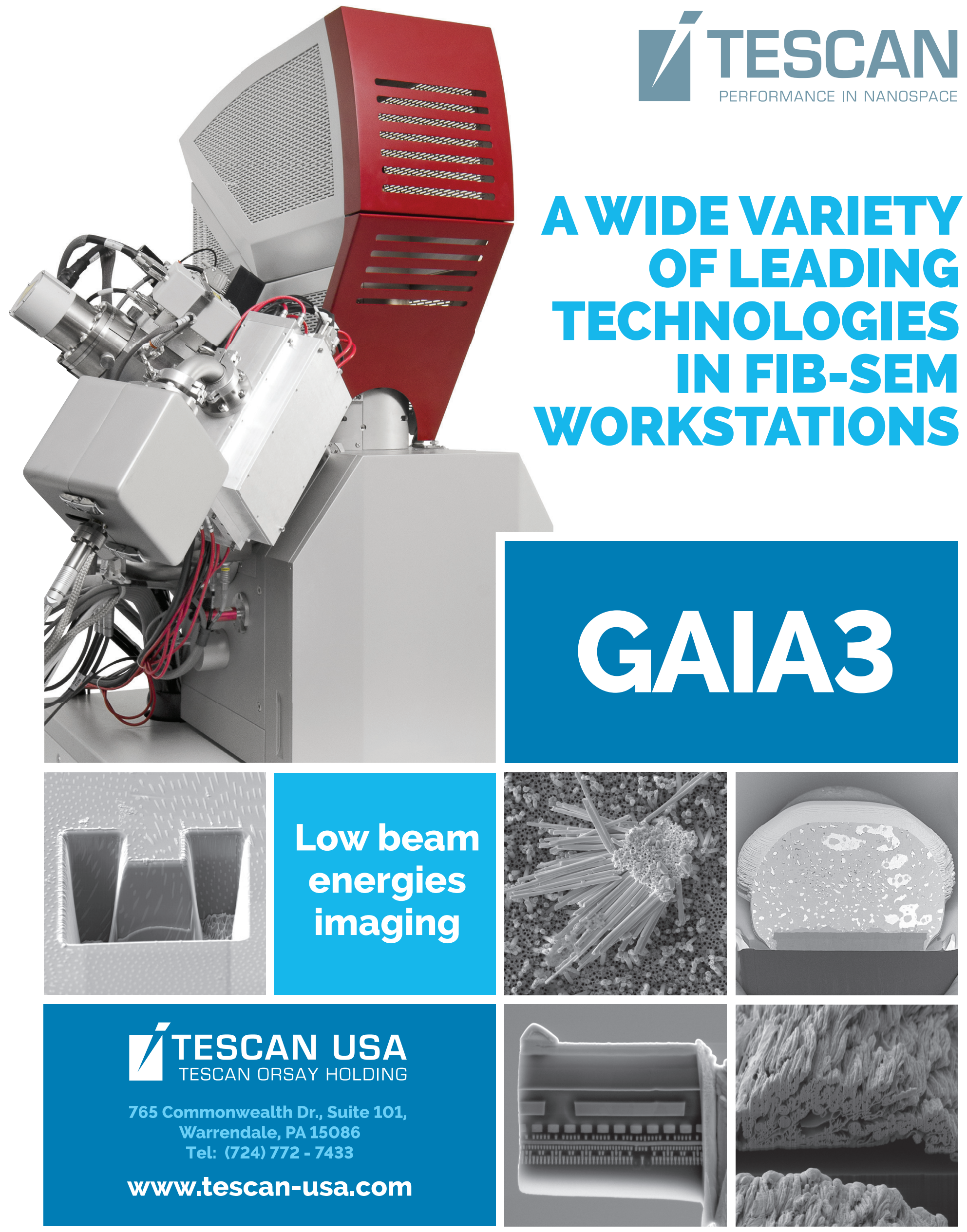

